\title{
Association of type of birth attendant and place of delivery on infant mortality in sub-Saharan Africa.
}

\author{
Whitney A. Stanley, Larissa R. Brunner Huber, Sarah B. Laditka, Elizabeth F. Racine
}

Department of Public Health Sciences, University of North Carolina at Charlotte, 9201 University City Boulevard, Charlotte, NC 28223; phone: 704-687-8719; fax: 704-687-1644;

\begin{abstract}
Objective: To examine the association between type of birth attendant and place of delivery, and infant mortality (IM). Methods: This cross-sectional study used self-reported data from the Demographic Health Surveys for women in Ghana, Kenya, and Sierra Leone. Logistic regression estimated odds ratios (ORs) and95\% confidence intervals.

Results: In Ghana and Sierra Leone, odds of IM were higher for women who delivered at a health facility versus women who delivered at a household residence $(\mathrm{OR}=3.18,95 \%$ confidence interval, $\mathrm{CI}: 1.29-7.83, \mathrm{p}=0.01$ and $\mathrm{OR}=1.62,95 \% \mathrm{CI}$ : $1.15-2.28, \mathrm{p}=0.01$, respectively). Compared to the use of health professionals, the use of birth attendants for assistance with delivery was not significantly associated with IM for women in Ghana or Sierra Leone (OR=2.17, 95\% CI: 0.83-5.69, p $=0.12$ and $\mathrm{OR}=1.25,95 \%$ CI: 0.92-1.70, $\mathrm{p}=0.15$, respectively). In Kenya, odds of IM, though nonsignificant, were lower for women who used birth attendants than those who used health professionals to assist with delivery (OR=0.85, 95\% CI: 0.51-1.41, $\mathrm{p}=0.46)$, and higher with delivery at a health facility versus a household residence (OR=1.29, 95\% CI: 0.81-2.03, $\mathrm{p}=0.28)$.

Conclusions: Women in Ghana and Sierra Leone who delivered at a health facility had statistically significant increased odds of IM. Birth attendant type-IM associations were not statistically significant.Future research should consider culturally-sensitive interventions to improve maternal health and help reduce IM.

Keywords: birth attendant, infant mortality, sub-Saharan Africa

DOI: http://dx.doi.org/10.4314/ahs.v16i1.1

Cite as: Stanley WA, Huber LRB, Laditka SB, Racine EF. Association of type of birth attendant and place of delivery on infant mortality in sub-Saharan Africa. Afri Health Sci. 2016;16(1): 1-9. bttp:// dx.doi.org/10.4314/abs.v16i1.1
\end{abstract}

\section{Introduction}

Infant mortality (IM), the death of a child occurring in the first year of life, accounted for 6.2 million deaths worldwide in $2010^{1}$. However, $99 \%$ of these deaths occurred in developing countries ${ }^{2}$. Nearly half $(46 \%)$ of the IM burden can be attributed to Africa, even though it only contributes to $15 \%$ of the world population ${ }^{1}$. Although substantial progress has been made in reducing the IM rate worldwide, sub-Saharan Africa (SSA) has made little progress towards this goal, reducing child mortality at an annual rate of $1 \%{ }^{3}$. Birth is the time of highest risk for infants, where 6 million stillbirths and neonatal deaths occur every year. Stillbirths, or late

\section{Corresponding author:}

Whitney A. Stanley,

Department of Public Health Sciences,

University of North Carolina at Charlotte,

9201 University City Boulevard, Charlotte, NC 28223

phone: 704-687-8719; fax: 704-687-1644;

Email: stanley.whitney@gmail.com fetal deaths, account for half of these deaths and are attributable to poor maternal health, poor prevention and treatment of maternal conditions and infections during pregnancy, and inappropriate management of complications during pregnancy and childbirth ${ }^{4}$. Neonatal deaths are attributable to infections, intrapartum conditions, and preterm birth complications while post-neonatal mortality is most often caused by infectious diseases $^{5}$. Failure to reach the Millennium Development Goal of improving birth outcomes by 2035 will result in approximately 116 million deaths, 99 million survivors with disabilities or lost development potential, and millions more at increased risk of non-communicable diseases after low birth weight ${ }^{5}$.

Most African countries began to place emphasis on expanding health care services during the 1970s and 1980s, increasing locally-coordinated maternal and child care services ${ }^{6}$. The expansion of maternal and child health services gave birth to the concept of skilled birth attendants (SBAs). SBAs required training traditional birth attendants (TBAs) to assume the role of encouraging prenatal care and family planning services after delivery, assisting with births in a culturally acceptable 
manner, and recognizing risk for delivery complications and referring those women to an appropriate health facility. Data show that in 1974, TBAs delivered 70-90\% of babies born in Africa ${ }^{6}$. Today that number has been reduced dramatically, with a $66 \%$ increase in SBAs. However, approximately 30 million women worldwide are still using TBAs for delivery ${ }^{7}$.

Research has examined several aspects of delivery attendants, focusing on the prevalence of TBA utilization and satisfaction with TBAs throughout developing countries $^{8-10}$. A study in rural Tanzania suggests that TBAs' maternal care methodology lacks consistency and often patients felt that their TBA was not adequately equipped ${ }^{8}$. The studies further suggest that TBAs rarely refer patients to skilled delivery attendants when complications occur with pregnancy ${ }^{9,10}$. However, despite the recognized consequences of using unskilled birth attendants, the majority of patients felt satisfied with the level of care they received during childbirth and would recommend their TBA to a friend or relative ${ }^{8,9}$. It is useful to better understand the role of TBAs to help address IM. Several studies have investigated the role of facility-based deliveries on neonatal mortality ${ }^{11,12}$. While areas of SSA with high facility-based delivery rates tend to have lower neonatal mortality rates, there are variations within the region ${ }^{11,12}$. To our knowledge, no research has examined associations between delivery conditions and IM in SSA. Therefore, this study sought to address this shortcoming in the literature by examining the association between birth attendant and place of delivery and IM in three SSA countries - Ghana, Kenya, and Sierra Leone - using routinely collected population-based data from Measure Demographic and Health Survey (DHS). We hypothesized that women who used health professionals and health facilities for childbirth would experience reduced odds of IM compared to women who used unskilled birth attendants and household residences for delivery.

\section{Methods}

\section{Study population}

This cross-sectional study used data from the 2008 DHS V. DHS provides technical assistance in survey implementation in developing countries to improve the understanding of health and population status and trends. DHS uses a two-stage cluster design to ensure that sample populations are representative at the national, regional, and residence levels. During sampling, enumeration areas (EAs) are drawn from census data; next, a sample of households from each EA is select- ed from an up-to-date list of households within the respective $\mathrm{EA}^{13}$.

The 2008 DHS Women's Questionnaire was used for this study. In addition to the human subject's protection safeguards employed by DHS, our study was approved by our university institutional review board. Inclusion criteria were being female and of reproductive age (15-49 years old). Women who agreed to participate in the DHS gave verbal consent to interviewers. Local, trained interviewers recorded participant's self-reported answers. Participants who did not provide responses for the variables of interest were excluded, including women who never had children or their most recent pregnancy did not result in a live birth (Ghana: $n=1617$, Kenya: $n=2342$, Sierra Leone: $n=1498)$, those missing information on delivery (Ghana: $\mathrm{n}=1155$, Kenya: $n=2024$, Sierra Leone: $n=1948$ ), education (Ghana: $n=2$ ), electricity (Kenya: $n=1$, Sierra Leone: $n=1$ ), religion (Ghana: $n=7$, Kenya: $n=31$, Sierra Leone: $n=21$ ), spouse information (Kenya: $n=2$ ), work status (Ghana: $n=9$, Kenya: 13, Sierra Leone: $n=24)$, immunizations (Ghana: $n=24$, Kenya: $n=8$ ), and those identifying their place of delivery as "other" (Ghana: $\mathrm{n}=11$, Kenya: $\mathrm{n}=5$, Sierra Leone: $n=26)$. Additionally, Ghana's DHS V survey included a unique category of delivery attendant called "community health officers." Since DHS notes that there is a lack of clarity regarding their competence and because the other countries do not have this category, we ultimately excluded them from analysis $(\mathrm{n}=322)$. The analytic dataset consisted of 1,767 women in Ghana, 4,018 in Kenya, and 3,856 in Sierra Leone.

\section{Exposure variables}

There were two exposure variables: place of delivery and type of delivery attendant. Women self-reported where their child was delivered and who assisted with the delivery. Women who indicated that a health professional (doctor, nurse, or auxiliary midwife) assisted in their delivery were considered to be exposed, while women who stated that a TBA or relative/friend assisted in their delivery were considered unexposed. Women who indicated delivery in a public or private health facility were considered exposed, while women who indicated delivery occurred in a household residence (including participants' residences, as well as those of family, friends, or midwives) were in the unexposed group.

\section{Outcome variable}

The outcome variable was IM, defined as the death of an infant before the first year of life. Women self-re- 
ported whether their most recent child had died and were asked how old the child was at time of death.

\section{Covariates}

Potential confounding variables considered were maternal age at delivery, whether the infant was breastfed, malnutrition, maternal immunizations, region of residence (rural versus urban), religion, maternal education level, prior history of child mortality, having electricity, partner's education level, employment status, marital status, prenatal care attendant, and parity ${ }^{10-12,14-17}$.

\section{Analysis}

Descriptive statistics summarized results for participants in each country. Multivariate logistic regression was used to calculate unadjusted and adjusted odds ratios (ORs) and 95\% CIs between birth attendant and place of delivery, and IM. Potential confounding variables were entered into the exposure-disease model one at a time and if the confounding variable altered the magnitude of the OR by atleast $10 \%$, it was considered to be a confounder of the exposure-disease associations ${ }^{18}$. We also performed a sensitivity analysis using neonatal mortality and post-neonatal mortality as the outcomes. An alpha level of $\mathrm{p}<0.05$ was used to identify statistically significant results. Weights were used to account for the complex sampling design and all analyses were performed using SAS Version 9.1 (Cary, NC).

\section{Results \\ Ghana}

Approximately 3\% of women reported IM resulting from their most recent birth. The majority of women had their most recent birth facilitated by a health professional $(85.2 \%)$ and at a health facility $(70.7 \%$; Table 1). In unadjusted models, women who used health personnel to assist with the delivery of their most recent birth had increased odds of IM compared to women who used a TBA or relative to assist with the delivery; however, this result was not statistically significant $(\mathrm{OR}=1.66,95 \% \mathrm{CI}: 0.69-3.99, \mathrm{p}=0.26$; Table $2)$. Women who delivered their most recent child at a health facility had increased odds of IM compared to women who delivered at a household residence; this result was statistically significant $(\mathrm{OR}=2.26,95 \% \mathrm{CI}$ : 1.15-4.44, $\mathrm{p}=0.02)$. After adjusting for education, partner's education level, region, and religion, women who used health personnel to assist with the delivery of their most recent birth had increased odds of IM compared with women who used a TBA or relative to assist with the delivery; this result increased in magnitude, but remained statistically insignificant $(\mathrm{OR}=2.17,95 \% \mathrm{CI}$ : 0.83-5.69, $\mathrm{p}=0.12$; Table 3). 
Table 1. Baseline Demographic, Lifestyle, and Birthing Characteristics of Participants in DHS V (2008), by Country.a

\begin{tabular}{|c|c|c|c|}
\hline & $\begin{array}{l}\text { Ghana } \\
(\mathrm{n}=1767)\end{array}$ & $\begin{array}{l}\text { Kenya } \\
(\mathrm{n}=4018)\end{array}$ & $\begin{array}{l}\text { Sierra Leone } \\
(\mathrm{n}=3856)\end{array}$ \\
\hline & $\mathrm{n}(\%)$ & $\mathrm{n}(\%)$ & $\mathrm{n}(\%)$ \\
\hline \multicolumn{4}{|l|}{ Infant Mortality } \\
\hline Yes & $61(3.4 \%)$ & $138(3.5 \%)$ & $248(6.2 \%)$ \\
\hline No & $1719(96.6 \%)$ & $3880(96.5 \%)$ & $3608(93.8 \%)$ \\
\hline \multicolumn{4}{|l|}{ Birth Attendant } \\
\hline Health Personnel & $1470(85.2 \%)$ & $2938(75.4 \%)$ & $2162(53.5 \%)$ \\
\hline [raditional Birth Attendant/Other & $297(14.7 \%)$ & $1080(24.6 \%)$ & $1694(47.5 \%)$ \\
\hline \multicolumn{4}{|l|}{ Place of Delivery } \\
\hline Health Facility & $1179(70.7 \%)$ & $1879(46.6 \%)$ & $1153(26.4 \%)$ \\
\hline Household Residence & $588(29.3 \%)$ & $2139(53.4 \%)$ & $2703(73.6 \%)$ \\
\hline \multicolumn{4}{|l|}{ Maternal Age (years) } \\
\hline $15-24^{\circ}$ & $423(23.6 \%)$ & $1389(33.8 \%)$ & $1092(27.7 \%)$ \\
\hline $25-34$ & $827(48.0 \%)$ & $1817(47.1 \%)$ & $1822(46.8 \%)$ \\
\hline $35-49$ & $517(28.5 \%)$ & $812(19.1 \%)$ & $942(25.5 \%)$ \\
\hline \multicolumn{4}{|l|}{ Breastfeeding } \\
\hline$>6$ months & $1720(97.2 \%)$ & $3836(96.1 \%)$ & $3728(97.1 \%)$ \\
\hline$\leq 6$ months & $47(2.8 \%)$ & $182(3.9 \%)$ & $128(2.9 \%)$ \\
\hline \multicolumn{4}{|l|}{$\begin{array}{l}\text { Supplement Intake (Iron and } \\
\text { Vit A) }\end{array}$} \\
\hline Yes & $1299(76.0 \%)$ & $1977(51.1 \%)$ & $2378(60.3 \%)$ \\
\hline No & $468(24.0 \%)$ & $2041(48.9 \%)$ & $1478(39.7 \%)$ \\
\hline \multicolumn{4}{|l|}{ Tetanus Immunizations } \\
\hline Yes & $1560(89.6 \%)$ & $533(11.2 \%)$ & $3384(86.3 \%)$ \\
\hline No & $207(10.4 \%)$ & $3445(87.9 \%)$ & $365(10.8 \%)$ \\
\hline \multicolumn{4}{|l|}{ Region } \\
\hline Urban & $686(43.5 \%)$ & $1061(20.4 \%)$ & $1396(29.1 \%)$ \\
\hline Rural & $1081(56.5 \%)$ & $2957(79.6 \%)$ & $2460(70.9 \%)$ \\
\hline \multicolumn{4}{|l|}{ Religion } \\
\hline Traditional & $128(5.5 \%)$ & $0(0 \%)$ & $6(0.2 \%)$ \\
\hline Muslim & $339(17.8 \%)$ & $716(8.0 \%)$ & $2909(79.4 \%)$ \\
\hline Christian & $1218(72.6 \%)$ & $3180(88.9 \%)$ & $914(19.6 \%)$ \\
\hline Other & $82(4.1 \%)$ & $122(3.0 \%)$ & $27(1.0 \%)$ \\
\hline \multicolumn{4}{|l|}{ Education Level } \\
\hline No Education & $618(29.5 \%)$ & $737(11.1 \%)$ & $2736(74.2 \%)$ \\
\hline Primary & $397(22.9 \%)$ & $2274(62.9 \%)$ & $522(12.7 \%)$ \\
\hline Secondary & $705(44.8 \%)$ & $770(21.0 \%)$ & $535(11.8 \%)$ \\
\hline Higher & $47(2.8 \%)$ & $237(5.0 \%)$ & $63(1.4 \%)$ \\
\hline \multicolumn{4}{|l|}{ Other Children Who Have } \\
\hline \multicolumn{4}{|l|}{ Died } \\
\hline Yes & $73(3.4 \%)$ & $152(3.6 \%)$ & $357(10.2 \%)$ \\
\hline No & $1694(96.6 \%)$ & $3866(96.4 \%)$ & $3499(89.8 \%)$ \\
\hline \multicolumn{4}{|l|}{ Electricity } \\
\hline Yes & $841(53.9 \%)$ & $724(17.3 \%)$ & $434(9.2 \%)$ \\
\hline No & $926(46.1 \%)$ & $3294(82.7 \%)$ & $3422(90.8 \%)$ \\
\hline Partner's Education Level & & & \\
\hline None & $464(17.4 \%)$ & $547(7.7 \%)$ & $2251(62.2 \%)$ \\
\hline Primary & $142(7.2 \%)$ & $1756(46.8 \%)$ & $336(8.6 \%)$ \\
\hline Secondary & $845(52.0 \%)$ & $1046(28.8 \%)$ & $652(15.1 \%)$ \\
\hline Higher & $150(9.1 \%)$ & $326(7.4 \%)$ & $179(4.0 \%)$ \\
\hline Missing & $166(14.5 \%)$ & $343(9.3 \%)$ & $438(10.0 \%)$ \\
\hline Currently Working & & & \\
\hline Yes & $1538(86.8 \%)$ & $2265(60.7 \%)$ & $2865(76.6 \%)$ \\
\hline No & $229(13.2 \%)$ & $1753(39.3 \%)$ & $991(23.4 \%)$ \\
\hline Married & & & \\
\hline Never & $92\left(5.9^{\%} \%\right)$ & $343(9.3 \%)$ & $337(7.5 \%)$ \\
\hline Currently & $1569(87.5 \%)$ & $3312(81.8 \%)$ & $3319(87.4 \%)$ \\
\hline Former & $106(6.6 \%)$ & $363(8.9 \%)$ & $200(5.1 \%)$ \\
\hline Prenatal Care Attendant & $62(3.1 \%)$ & $377(7.3 \%)$ & $208(6.6 \%)$ \\
\hline None & $1589(91.5 \%)$ & $3599(91.6 \%)$ & $2335(60.3 \%)$ \\
\hline Health Personnel & $116(5.5 \%)$ & $42(1.1 \%)$ & $1313(33.1 \%)$ \\
\hline Traditional Birth & & & \\
\hline Attendant/Other & & & \\
\hline Parity & & & \\
\hline 1 & $399(23.6 \%)$ & $863(21.2 \%)$ & $795(18.8 \%)$ \\
\hline 2 & $361(20.9 \%)$ & $836(21.1 \%)$ & $797(20.4 \%)$ \\
\hline 3 & $300(17.0 \%)$ & $693(17.4 \%)$ & $620(16.6 \%)$ \\
\hline 4 & $236(14.0 \%)$ & $492(12.2 \%)$ & $525(13.4 \%)$ \\
\hline 5 & $173(9.3 \%)$ & $356(8.9 \%)$ & $395(10.6 \%)$ \\
\hline $6+$ & $298(15.1 \%)$ & $778(19.2 \%)$ & $724(20.2 \%)$ \\
\hline
\end{tabular}


Table 2. Association between Select Demographic, Lifestyle, and Birthing Characteristics and Infant Mortality; Standard DHS V (2008).

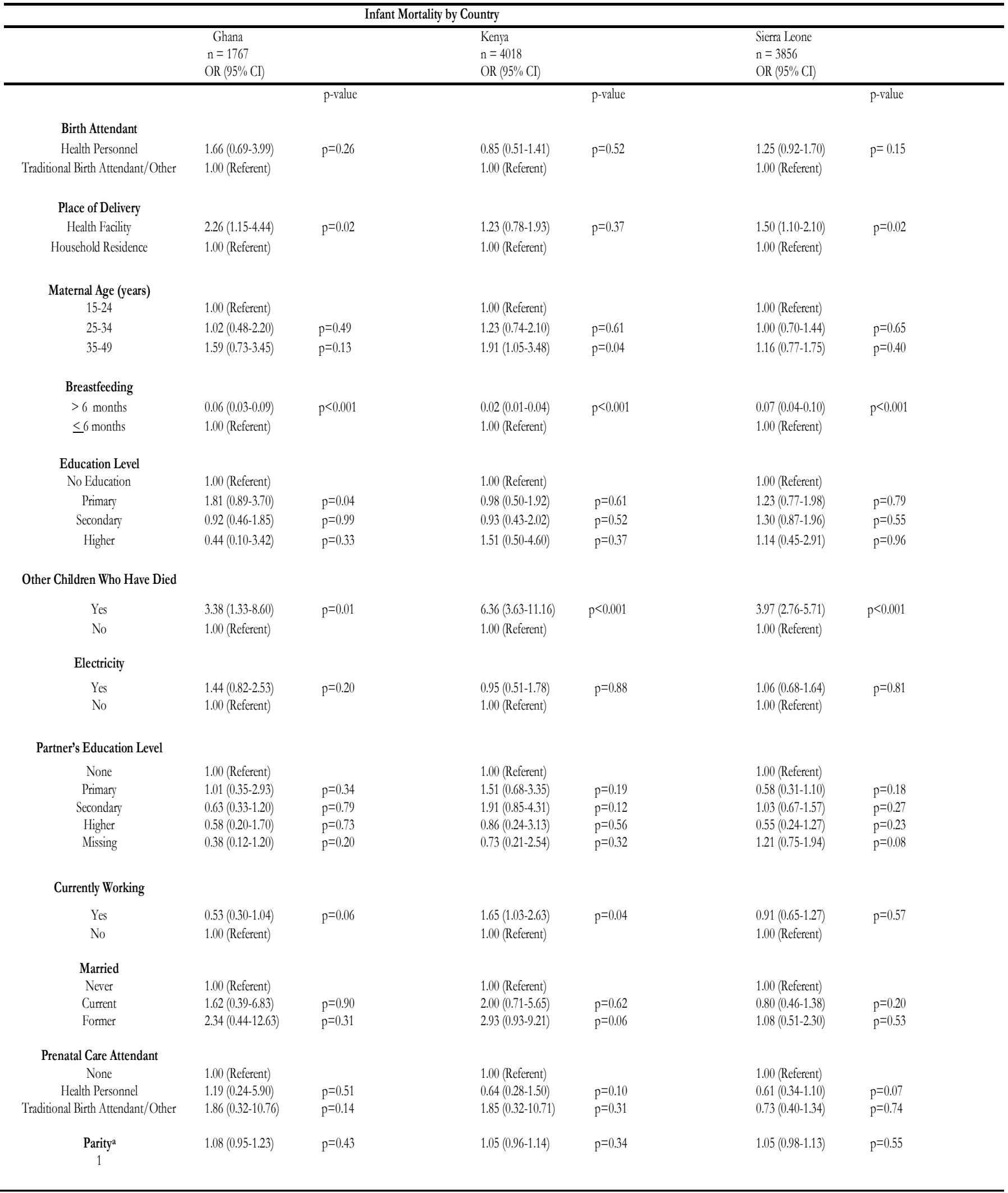

a Treated as a continuous variable 


\begin{tabular}{|c|c|c|c|c|c|c|}
\hline \multicolumn{7}{|c|}{ Infant Mortality by Country } \\
\hline & \multicolumn{2}{|l|}{$\begin{array}{l}\text { Ghana } \\
\mathrm{n}=1767 \\
\text { OR }(95 \% \mathrm{CI})\end{array}$} & \multicolumn{2}{|l|}{$\begin{array}{l}\text { Kenya } \\
\mathrm{n}=4018 \\
\text { OR }(95 \% \mathrm{CI})\end{array}$} & \multicolumn{2}{|l|}{$\begin{array}{l}\text { Sierra Leone } \\
n=3856 \\
\text { OR }(95 \% \text { CI })\end{array}$} \\
\hline & & p-value & & $\mathrm{p}$-value & & $\mathrm{p}$-value \\
\hline \multicolumn{7}{|l|}{ Birth Attendant } \\
\hline Health Personnel & $2.17(0.83-5.69)^{\mathrm{a}}$ & $\mathrm{p}=0.12$ & $0.85(0.51-1.41)^{\mathrm{b}}$ & $\mathrm{p}=0.46$ & $1.25(0.92-1.70)^{\mathrm{b}}$ & $\mathrm{p}=0.15$ \\
\hline $\begin{array}{l}\text { Traditional Birth } \\
\text { Attendant/Other }\end{array}$ & 1.00 (Referent) & & 1.00 (Referent) & & 1.00 (Referent) & \\
\hline $\begin{array}{l}\text { Place of Delivery } \\
\text { Health Facility } \\
\text { Household Residence }\end{array}$ & $\begin{array}{l}3.18(1.29-7.83)^{c} \\
1.00 \text { (Referent) }\end{array}$ & $\mathrm{p}=0.01$ & $\begin{array}{l}1.29(0.81-2.03)^{\mathrm{d}} \\
1.00 \text { (Referent) }\end{array}$ & $\mathrm{p}=0.28$ & $\begin{array}{l}1.62(1.15-2.28)^{\mathrm{e}} \\
1.00 \text { (Referent) }\end{array}$ & $\mathrm{p}=0.01$ \\
\hline
\end{tabular}

aAdjusted for Education, Partner's Education Level, Region, and Religion.

b No variables met criteria for confounding and unadjusted results were retained.

cAdjusted for Education, Electricity, Immunizations, Partner's Education Level, Region, Religion, and other children that have died.

d Adjusted for Education, Electricity, Immunizations, and Partner's Education Level.

e Adjusted for Education, Electricity, Immunizations, Partner's Education Level, and Religion.

After adjusting for education, electricity, immunizations, partner's education, region, religion, and other children who have died, the place of delivery and IM association increased in magnitude and remained statistically significant $(\mathrm{OR}=3.18,95 \%$ CI: 1.29-7.83, $\mathrm{p}=0.01)$.

\section{Kenya}

In Kenya, 3.5\% of women reported infant mortality resulting from their most recent birth. The majority of participants had their most recent birth attended by health personnel $(75.4 \%)$, but they delivered at a household residence $(53.4 \%)$ (Table 1). In the unadjusted model, women who used health personnel to assist with the delivery of their most recent birth had decreased odds of IM compared with women who used a TBA or relative to assist with the delivery; however, this result was not statistically significant (OR $=0.85,95 \% \mathrm{CI}$ : 0.51-.41, $\mathrm{p}=0.52$; Table 2). Women who delivered their most recent child at a health facility had slightly increased odds of IM compared to women who delivered at a household residence; however, this result was not statistically significant $(\mathrm{OR}=1.23,95 \% \mathrm{CI}$ : $0.78-1.93$, $\mathrm{p}=0.37$ ). Based on confounder selection strategies, no confounding variables were found to alter the OR by $10 \%$ or more, and an adjusted analysis was not necessary for delivery attendant $\mathrm{t}^{14}$. After adjusting for education, electricity, immunizations, and partner's education level, the magnitude of the place of delivery and IM association remained largely unchanged $(\mathrm{OR}=1.29,95 \%$ CI: $0.81-2.03, \mathrm{p}=0.28$; Table 3).

\section{Sierra Leone}

Six percent of women reported IM resulting from their most recent birth. The majority of women used health personnel to assist with the delivery of their most recent child $(53.5 \%)$ and delivered in a household residence $(73.6 \%)$ (Table 1). In unadjusted models, women who used health personnel for the delivery of their most recent child had increased odds of IM compared with women who used a TBA or relative to assist the delivery; however, this result was not statistically significant $(\mathrm{OR}=1.25,95 \%$ CI: 0.92-1.70, $\mathrm{p}=0.15$; Table 2). Women who delivered their most recent child at a health facility had significantly increased odds of IM compared with women who delivered at a household residence; this result was statistically significant $(\mathrm{OR}=1.50,95 \%$ CI: 1.10-2.10, $\mathrm{p}=0.02$; Table 2). Based on confounder selection strategies, no confounding variables were identified, and an adjusted analysis was not necessary for delivery attendant. After adjusting for education, electricity, immunizations, partner's education, and religion, the place of delivery and IM association increased in magnitude and remained statistically significant. Women who delivered at a health facility had 1.62 times the odds of IM compared to women who delivered at a household residence ( $95 \%$ CI: 1.15-2.28, $\mathrm{p}=0.01$; Table 3).

\section{Sensitivity analysis}

More than half of deaths in the three populations were neonatal deaths: Ghana: $63.9 \%$, Kenya: $52.4 \%$, Sierra 
Leone: $59.4 \%$ (results of sensitivity analyses not shown in tables). We reanalyzed the data using both neonatal mortality and post-neonatal mortality as the outcomes. In unadjusted and adjusted analyses, the direction of the results remained unchanged and the magnitude of the associations were similar or increased for both outcomes. Since there were fewer women who had a neonatal death or post-neonatal death versus IM, all of the confidence intervals were much wider. To illustrate, the adjusted findings for the facility delivery-IM association versus the facility delivery-neonatal mortality association were: Ghana: OR=3.18 (95\% CI: 1.29-7.83) vs. $\mathrm{OR}=7.88$ (95\% CI: 2.46-25.24); Kenya: $\mathrm{OR}=1.29$ (95\% CI: 0.81-2.03) vs. OR=1.51 (95\% CI: 0.81-2.81); and Sierra Leone: OR=1.62 (95\% CI: 1.15-2.28) vs. $\mathrm{OR}=2.18$ (95\% CI: 1.38-3.46).

\section{Discussion}

In this study, we found no statistically significant associations between the use of health professionals during childbirth and IM for women in Ghana, Kenya, and Sierra Leone. This result was not consistent with our hypothesis. The lack of significance may be due in part to the fact that a large majority of women used health care professionals, particularly in Ghana and Kenya.

Our second hypothesis, that delivering a child at a health facility would be associated with reduced odds of IM compared to delivering at a household residence, was also not supported. In all three countries, delivering in a health facility was associated with increased odds of IM; these findings were statistically significant for Ghana and Sierra Leone. There may be several reasons for these counterintuitive findings. First, this study considered IM, rather than neonatal mortality, as the outcome. The majority of women in our study populations had neonatal deaths. Since the results of the sensitivity analysis that used neonatal mortality as the outcome were in the same direction and of similar magnitude, we retained IM as the outcome to increase the sample size and precision. Most studies have found that areas with high SBA and facility-based delivery use have lower neonatal mortality ${ }^{12}$. However, consistent with the findings of the present study, some researchers have found the opposite to be true ${ }^{12}$, though there is no data to explain this phenomenon. It is possible that women with higher risks were more likely to be referred for a facility-based delivery and use health professionals during childbirth, particularly in Ghana and Sierra Le- one. The complications associated with these high-risk pregnancies may have been so severe that medical interventions were unsuccessful in preventing IM. Further research is needed to determine why delivery at a health facility would be associated with an increased risk of IM.

There were differences in the magnitude and direction of results for the countries studied. These differences point to the potential importance of the role of cultural beliefs and norms of whether women use health facilities and professionals for delivery. Religion, traditional birth practices, community attitudes, and the decision-making process within families all interact to determine whether a woman will use healthcare resources, and these factors and their importance differ not only within countries in SSA, but also within regions ${ }^{11,12,19}$.

\section{Limitations}

This study has several limitations. Although DHS is comprehensive, it does not include a number of questions that are culturally-informed to account for variations that exist among cultures. For example, "chichuru," the infanticide prevalent in Ghana when a child is believed to be cursed due to physical abnormalities, was not acknowledged by DHS. Allotey and Reidpath ${ }^{20}$ suggest that as many as $15 \%$ of infant deaths in Ghana under the age of 3 years result from tribal belief in "chichuru." Thus, there may be opportunities to improve the cultural sensitivity and specificity of the survey for SSA countries. Additionally, both exposures examined in this study, attendant present at birth and place of delivery, were measured using self-report. As a result, nondifferential misclassification may have occurred if participants did not understand the definitions of health personnel, TBA, and health facility. Selection bias may be present with DHS, as not all eligible women may be willing to participate in the study or barriers to access could have occurred as a result of language, literacy, and rural location. However, the response rates for women in the studied countries were all over $94 \%{ }^{21-23}$. Thus, selection bias for the present study is limited. Recall bias may have occurred. In instances where the child died before the first year of birth, it is possible that the mother will remember circumstances regarding the care and delivery of that child in greater detail. Additionally, this study did not take into account pregnancy complications that could attribute to both the use of both health personnel and a health facility during childbirth. 
The present study also has several strengths. DHS data on IM in developing countries are highly regarded for their quality and are a predominant source of data for empirical studies examining delivery conditions in $\mathrm{SSA}^{11,24}$. The Women's Questionnaire is comprehensive and trained interviewers were present to assist participants. While most studies have considered neonatal mortality, this study investigated IM and whether the use of health facilities and professionals extended any protection beyond the early neonatal period. Sample sizes for each country were large and representative at the national, regional, and residence levels; this suggests that results may be generalizable, however, regional differences within SSA should be considered.

\section{Conclusion}

The findings suggest that the use of health personnel for delivery assistance and health facilities for childbirth is more common in SSA than expected. However, rates of IM are still alarmingly high in these developing countries. Maternal factors have been largely explored by household demographic surveillance surveys, but these do little to represent social and cultural factors that vary by region. Data collection on social factors, such as community attitudes and the decision-making process, is critical to better understand how women view health professionals and facilities. Interventions to improve delivery outcomes would benefit from data that are comprehensive in both maternal and social factors ${ }^{11}$.

Research by O'Rourke ${ }^{25}$ suggests that training programs designed to build a network between health facilities for obstetric referrals and TBAs can be successful in increasing patient referrals and improving patient satisfaction: a training intervention was created to help facilitate a mutual relationship between health personnel and TBAs and reduce $\mathrm{IM}^{25}$. Using a similar approach, future interventions could improve maternal health during the preconception and prenatal period by increasing the knowledge exchanged between delivery attendants who have clinical skills and TBAs who possess familiarity with traditional and cultural norms. For example, this exchange of information could improve efforts to educate women on the importance of immunizations and proper nutrition to improve their own health and the health of their children, and ensure that women are aware of community-based resources that are available to them. Future research should further examine the association between delivery conditions and poor delivery outcomes, placing special emphasis on improving cultural sensitivity by region to help reduce IM.

\section{Conflict of interest}

We certify that there is no conflict of interest with any financial organization regarding the material discussed in this article.

\section{References}

1. Institut National D'edtudes Demographiques. Infant mortality across the world. 2010 Dec 13. Retrieved from http://www.ined.fr/en/everything_about_population/teaching_kits/length_of_life_death_mortality/ infant_mortality_world/

2. Andrews, KM, Brouillette, DB, Brouillette, RT. Mortality, infant. Encyclopedia of Infant and Early Childhood Development; 2008: 343-359. doi: 10.1016/B978012370877-9.00084-0

3. Mason, B. Unicef report: infant mortality rates still high. World Socialist Web Site. 2008. Retrieved from http://www.wsws.org/articles/2008/jan2008/ mort-j31.shtml

4. Darmstadt, GL, Yakoob, MY, Haws, RA, Menezes, EV, Soomro, T, et al. Reducing Stillbirths: interventions during labor. BMC Pregnancy Childbirth 2009; 9(Suppl 1): S6. doi: 10.1186/1471-2393-9-S1-S6

5. Lawn, JE, Blencowe, H, Oza S, You, D, Lee ACC, et al. Every Newborn: progress, priorities, and potential beyond survival. The Lancet 2014; 384(9938):189 -205 PubMed. doi: 10.1016/S0140-6736(14)60496-7

6. Eades, CA, Brace, C, Osei, L, LaGuardia, KD. Traditional birth attendants and maternal mortality in Ghana. Soc Sci Med 1993; 36(11): 1503-1507. doi: 10.1016/02779536(93)90392-H

7. Byrne, A, Morgan, A. How the integration of traditional birth attendants with formal health systems can influence and increase skilled birth attendance. Int J Gynecol Obstet 2011; 115(2): 127-134. doi: 10.1016/j. ijgo.2011.06.019

8. Mbaruku, G, Msambichaka, B, Galea, S, Rockers, P, Kruk, M. Dissatisfaction with traditional birth attendants in rural Tanzania. Int J Gynecol Obstet 2009; 107(1): 8-11. doi: 10.1016/j.ijgo.2009.05.008

9. Abioye-Kuteyi, EA, Elias, SO, Familusi, AF, Fakunle, A, Akinfolayan, $\mathrm{K}$. The role of traditional birth attendants in Atakumosa, Nigeria. J R Soc Promot Health 2001;121(2): 119-124. Retrieved from http://rsh.sagepub.com.librarylink.uncc.edu/content/121/2/119.full. pdf html

10. Paul, BK, Rumsey, DJ. Utilization of health facilities and trained birth attendants for childbirth in rural Bangladesh. Soc Sci Med 2002; 54: 1755-1765. doi: 10.1016/ S0277-9536(00)00207-0.Retrieved fromhttp://www.sciencedirect.com.librarylink.uncc.edu/science?_ob=Mi- 
amiImageURL\&_cid $=271821 \&$ \&user $=628632 \&$ _ pii $=$ S0277953601001484\&_check $=y \&$ \&_coverDate $=2002-06-01 \& v i e w=c \& w c h p=d G L z V B A-z S k-$ WA\&md5=03cde16669d900a3c2a613fb59ef0309/1-s2 .0-S0277953601001484-main.pdf

11.Moyer, CA, Mustafa, A. Drivers and deterrents of facility delivery in sub-Saharan Africa: a systematic review. Reprod Health 2013; 10(1): 40 PubMed .

12. Moyer, CA, Ddako-Gyeke, P, Adanu, RP. Facility-based delivery and maternal and early neonatal mortality in sub-Saharan Africa: A regional review of the literature. African Journal of Reproductive Health 2013; 17(3): 30-43.

13. Measure DHS. DHS Methodology. 2011. Retrieved from http://www.measuredhs.com/What-We-Do/ Survey-Types/DHS-Methodology.cfm

14. Gyimah, S, Takyi, B, Addai, I. Challenges to the reproductive-health needs of African women: On religion and maternal health utilization in Ghana. Soc Sci Med 2006;62(12): 2930-2944. doi: 10.1016/j. socscimed.2005.11.034

15. Golding, J, Emmett, P \& Rogers, I. Breast feeding and infant mortality. Early Hum Dev 1997; 49: S143-S155. doi: 10.1016/S0378-3782(97)00060-1

16. Greenwood, B. Maternal immunisation in developing countries. Vaccine 2003; 21(24): 3436-3441. doi: 10.1016.S0264-410X(03)00346-3

17. Fickling, D. Sub-Saharan malnutrition worse than 10 years ago. The Guardian 2005. Retrieved from http:/ / www.guardian.co.uk/world/2005/nov/22/hearafrica05.development

18. Maldonado G, Greenland. Simulation study of confounder-selection strategies. Am J Epidemiol 1993; 138: 923-36 PubMed .
19. The Maternity Alliance. Experiences of maternity services: Muslim women's perspectives. 2004. Retrieved from http://www.maternityaction.org.uk/sitebuildercontent/sitebuilderfiles/muslimwomensexperiencesofmaternityservices.pdf

20. Allotey, P, Reidpath, D. Establishing the causes of childhood mortality in Ghana: the 'spirit child'. Soc Sci Med 2001; 52(7): 1007-1012. doi: 10.1016/S02779536(00)00207-0

21. Ghana Statistical Service (GSS), Ghana Health Service (GHS), and ICF Macro. 2009. Ghana Demographic and Health Survey 2008: Key Findings. Retrieved from http://www.measuredhs.com/pubs/pdf/ FR229/FR229.pdf

22. Kenya National Bureau of Statistics and ICF Macro. 2008-09 Kenya Demographic and Health Survey: Key Findings. 2010. Retrieved from http:/ /www.measuredhs.com/pubs/pdf/FR229/FR229.pdf

23. Statistics Sierra Leone and ICF Macro. Sierra Leone Demographic and Health Survey 2008: Key Findings. 2009. Retrieved from http://www.measuredhs.com/ pubs/pdf/FR229/FR229.pdf

24. Rutstein, SO. Effects of preceding birth intervals on neonatal, infant, and child mortality and nutritional status in developing countries: evidence from the Demographic and Health Surveys. Demographic and Health Surveys Methodological Reports 2005; 89(1): S7-S24. doi: 10.1016/j.ijgo.2004.11.012

25. O'Rourke, K. The effect of hospital staff training on management of obstetrical patients referred by traditional birth attendants. Int J Gynecol Obstet 1995; 48: S95-S102. doi: 10.1016/0020-7292(95)02324-6229.pdf 